\title{
An Analytical Approach to the Welfare Cost of Business Cycles and the Benefit from Activist Monetary Policy
}

\author{
Michael T. Kiley ${ }^{1}$ \\ First Draft: December 2000 \\ This Draft: October 2001
}

${ }^{1}$ Address: Mail Stop 67, Federal Reserve Board, Washington, DC 20551. Email: mkiley@ frb.gov. Acknowledgements: I would like to those who commented on this work in presentations at the Federal Reserve Board and the 2001 Summer Meetings of the Econometric Society, especially Darrel Cohen, John Knowles, and Andrew Levin. The views expressed herein are those of the author, and do not necessarily represent those of the Federal Reserve Board or its staff. 


\title{
An Analytical Approach to the Welfare Cost of Business Cycles and the Benefit from Activist Monetary Policy
}

\begin{abstract}
Typical dynamic general-equilibrium (DGE) models with stochastic productivity, consumers with state-separable (expected utility) preferences, and capital accumulation imply a small welfare cost of business cycles and a small market price of risk (i.e., equity premium). I present an analytical solution to quantity and asset-price movements in a DGE model with preferences that are either state-separable or non-state-separable; nonstate separable preferences leave the response of quantities to productivity shocks unaltered from the solutions under expected utility, but can raise substantially the welfare cost of fluctuations or the equity premium implied by the model. I then show that a large welfare loss to business cycles does not imply a large gain from an activist monetary policy. In particular, monetary policy can implement the optimal allocation in a stickyprice version of the model, but the welfare gain from such a policy is trivial because the optimal allocation continues to imply a volatile consumption stream in response to productivity shocks. These results highlight an important distinction between recent new-Keynesian or neo-Monetarist models of business cycles and older Keynesian-style models: In the recent literature, economic fluctuations are largely an efficient response to shocks to the economy (and the deviations from efficiency stem primarily from relative price distortions associated with price rigidity-i.e., Harberger triangles). In the older literature, fluctuations were viewed as inherently inefficient (with larger inefficienciesi.e., Okun's gaps). In both literatures, this distinction is largely assumed rather than discovered, and the proper view of this distinction is the key determinant of the potential benefit of stabilization policy.
\end{abstract}

JEL Codes: E32, E52, E63, G12

Keywords: Non-expected utility; Business cycles; Stabilization policy; Asset pricing 


\section{Introduction}

Business cycle research remains very active, despite the provocative suggestion of Lucas (1987) that business cycle fluctuations, at least in the United States, are relatively unimportant for welfare. The size of the welfare losses from fluctuations and the gain from stabilization policy are analyzed below in a dynamic general equilibrium model with consumers who maximize preferences that are state-separable (expected utility) or not separable across states (Epstein-Zin-Weil preferences).

One surprising conclusion is that the benefit from an activist monetary policy is likely to be trivial in a typical sticky-price business cycle model, even when the welfare loss from fluctuations is arbitrarily large. For example, in the model below the representative consumer would give up a very large share of the level of productivity (greater than 20 percent) in order to completely eliminate consumption variability for calibrations that match the equity premium and risk-free rate; nonetheless, the consumer would sacrifice only about $1 / 10000^{\text {th }}$ percent of productivity for the stabilization benefits from the optimal monetary policy. ${ }^{1}$

This result arises because fluctuations in the model are primarily driven by exogenous shocks to productivity, as in most of the recent "neo-Monetarist" or "NewKeynesian" literature that embeds sticky prices in dynamic general equilibrium (DGE) models. Under these assumptions, fluctuations are primarily — though not exclusivelyan efficient response to shifts in the economic environment, and hence optimal stabilization policy only improves welfare slightly. The small gains to stabilization policy suggests that the recent surge in work deriving optimal monetary policies in environments similar to that of this paper (following Rotemberg and Woodford (1997)) may have misplaced its focus; it may be more fruitful to examine whether quantitative DGE models in which fluctuations are largely inefficient—perhaps because of sunspots or shifts among multiple pareto-ranked equilibria—are plausible characterizations of

\footnotetext{
${ }^{1}$ It is very important to draw a distinction between the stabilization benefit delivered by monetary policy, and the benefits that arise from different inflationary policies; the latter policies affect steady-state distortions (such as inflation tax effects). This research focuses solely on stabilization, as much recent research has been devoted to finding monetary policy rules to stabilize the economy (e.g., Taylor (1999)).
} 
fluctuations, as the large loss from fluctuations derived below suggest that in such environments the gains to stabilization policy could be quite large. ${ }^{2}$

The model provides an analytic characterization of fluctuations in quantities, asset prices, and welfare in a model with preferences that are not separable across states. With Epstein-Zin-Weil preferences, the intertemporal elasticity of substitution need not equal the inverse of the coefficient of relative risk aversion. In the model below, quantity fluctuations do not depend on risk aversion, while asset prices and welfare do depend on risk aversion. Therefore, increasing risk aversion does not affect the variance of consumption, but raises greatly the welfare costs of this variance. Tallarini (2000) contains a similar result on risk aversion, showing that quantity fluctuations are almost independent of risk aversion in a similar model. However, the model used therein does not contain an analytical solution, and hence Tallarini must use numerical techniques that are unfamiliar to many economists, as discussed below. The analytical solutions below complement the numerical exercises in Tallarini (2000), and make the consideration of a sticky-price model tractable. The emphasis on analytical solutions as an aid to understanding follows many recent contributions. ${ }^{3}$

Section 2 presents the economic environment and the solutions for quantity fluctuations. Section 3 considers the implications of the model for welfare and asset prices. Section 4 introduces a sticky-price version of the model and analyzes the gains from an optimal stabilization policy. Section 5 concludes.

\section{The Economic Environment and Optimal Allocation}

The economic environment draws on previous work that presents model economies with explicit analytical solutions. An early example is Long and Plosser (1983), who show that an analytical solution for economic fluctuations can be found in a model with state-

\footnotetext{
${ }^{2}$ The gains to an activist monetary policy reflect the limited role aggregate demand management plays in DGE models that have been developed to date. Some research examining the welfare cost of business cycles has emphasized the interaction between aggregate shocks and idiosyncratic consumption risk; in such models, it may be possible for policies that provide insurance against idiosyncratic risk associated with the business cycle to increase welfare, but the link between such insurance policies and stabilization policy, as typically defined, is tenuous and not often developed in the existing literature. Storesletten, Telmer, and Yaron (2000) is a recent example.

${ }^{3}$ E.g., Long and Plosser (1983), Basu (1987), Hercowitz and Sampson (1991), Benassy (1995), and Abel (1999).
} 
separable preferences over consumption that are logarithmic if capital depreciates fully after one period. Hercowitz and Sampson (1991) present a generalization of the Long and Plosser model in which capital can last for more than one period, so long as capital accumulation is subject to adjustment costs that make next period's capital a CobbDouglas aggregate of today's capital stock and investment level. Benassy (1995) extends this model to a sticky-wage, monetary environment.

The model below is an extension of the Hercowitz and Sampson (1991) and Benassy (1995) model that allows for preferences that are not state-separable (EpsteinZin-Weil preferences); when the intertemporal elasticity of substitution is one, the analytic solution for quantity variables is the same as that implied by the model with expected utility consumers whose intertemporal elasticity of substitution/coefficient of relative risk aversion is one. The results imply that we can solve for an analytical characterization of welfare and asset prices in a dynamic general equilibrium model with capital accumulation even when preferences are not state-separable. While the results are only a special case (requiring certain restrictions on preferences and capital stock adjustment), the solution provides a clear view of the factors important for welfare and asset prices, and hence complements the numerical exercises in Tallarini (2000), who numerically investigates the implications of non-expected utility consumers for business cycles and asset prices in a DGE model. This may be particularly useful for a model with non-expected utility consumers, because in this case the log-linear methods that many economists use to approximate solutions of DGE models are inappropriate, and hence Tallarini (2000) uses numerical techniques that are less familiar to many economists.

The economic environment can be completely characterized in a flexible-price version of the model by considering the production technology used by firms, the preferences of consumers, and the aggregate resource constraints. The solution of the social planner's problem will yield the optimal allocations of consumption and leisure over time, which also correspond to the flexible price, competitive equilibrium.

\section{A. Production Technology}

Firms produce output (Y) with capital (K) and labor input (L). The production function is Cobb-Douglas, and an aggregate productivity shock $(\mathrm{Z})$ shifts the production function over time 
Equation $1 \quad Y_{t}=Z_{t} K_{t}^{a} L_{t}^{1-a}, 0<a \leq 1$.

The aggregate technology shock follows the exogenous stochastic process

Equation $2 \quad Z_{t}=Z_{t}^{*} e^{\rho\left(\ln Z_{t-1}-\ln Z_{t-1}^{*}\right)+e_{t}},|\rho| \leq 1, e_{t} \sim N\left(0, \sigma^{2}\right), Z_{t}^{*}=Z_{t-1}^{*} e^{g}, g \geq 0$.

Aggregate technology has a lognormal distribution; when $\rho$ equals one, (log) aggregate technology is a random walk with non-negative drift $g$, and, for $\rho$ less than one (in absolute value), aggregate technology is a trend-stationary process.

B. Consumer Preferences

The representative consumer's preferences (U) are defined recursively by

\section{Equation 3}

$U_{t}=\ln C_{t}+\theta \ln \left(L-L_{t}\right)+\frac{\beta(1+\theta)}{(1-\beta)(1-\chi)} \ln E_{t}\left\{e^{\frac{(1-\beta)(1-\chi)}{(1+\theta)} U^{t+1}}\right\}, \theta \geq 0, \chi>0,0<\beta<1$,

where $E\{\}$ is the mathematical expectations operator, $C$ represents consumption, and the remaining symbols represent parameters of the utility function. This recursive definition of preferences allows for a separation of the intertemporal elasticity of substitution (which equals one in equation 3, as shown in section 3 below) and the coefficient of relative risk aversion as in Epstein and Zin (1989,1990,1991) and Weil (1990). These preferences differ from Epstein-Zin-Weil preferences in including the utility from leisure (which equals the difference between the consumer's time endowment and labor, L- $\mathrm{L}_{\mathrm{t}}$ ). Tallarini (1996) shows that the coefficient of relative risk aversion over atemporal wealth gambles implied by equation 3 is $\frac{\chi+\theta}{1+\theta}$. When $\chi$ equals one, the recursion in equation 3 collapses to the standard expected utility case, in which the coefficient of relative risk aversion equals the inverse of the intertemporal elasticity of substitution (i.e., one); when $\chi$ differs from one, the recursion in equation 3 implies that preferences are not separable across states, and the coefficient of relative risk aversion differs from the inverse of the intertemporal elasticity of substitution. Notably, $\chi$ greater than one implies that consumers are more risk averse than under expected utility.

C. Resource Constraints 
The resource constraints in the economy are relatively standard. Production equals consumption plus investment, and labor input must be less than or equal to the consumer's time endowment

Equation $4 \quad Y_{t}=C_{t}+I_{t}$,

Equation $5 \quad L_{t} \leq L$.

When $\theta$ equals zero (so there is no disutility from work), equation 5 will always bind, while for $\theta$ greater than zero, equation 5 will never bind. Below, only cases where $\theta$ is greater than zero will be considered, as only these cases allow for interesting effects of stabilization policy. ${ }^{4}$

Capital accumulation is governed by

Equation $6 \quad K_{t+1}=K_{t}^{1-d} I_{t}^{d}, 0 \leq d \leq 1$

where $\mathrm{d}$ is like a depreciation rate. According to equation 6, next period's capital stock is increasing in the current period's capital stock and level of investment, but the relationship is not linear as in a typical capital accumulation equation with geometric depreciation. Importantly, there are decreasing returns to investment—much like standard adjustment costs of investment. Both because equation 6 captures a form of adjustment costs and because it yields analytical solutions in some models-a point to which we return in the following discussion-a spate of recent work has adopted this form (e.g., Basu (1987), Hercowitz and Sampson (1991), Benassy (1995), and Abel (1999)).

\section{The Optimal Allocation}

The optimal allocation of consumption, investment, and leisure is the solution of a benevolent social planner's maximization of utility-equation 3-subject to the technological and resource constraints-equations $1,4,5$, and 6. The optimal allocation is also the result of the decentralized, competitive allocation under flexible prices, using standard arguments (Sargent (1987)).

\footnotetext{
${ }^{4}$ This will be clarified in section 4 below, but the argument is simple; if labor supply is inelastic, then output is solely determined by today's capital stock and level of productivity, and hence monetary policy will be completely ineffective in any attempt to affect output.
} 
The first-order conditions for consumption, investment, next period's capital stock, and leisure are

Equation $7 \quad \frac{1}{C_{t}}=\lambda_{t}$,

Equation $8 \quad \lambda_{t}=d\left(\frac{K_{t}}{I_{t}}\right)^{1-d} q_{t}$

Equation $9 \quad q_{t}=\beta E_{t}\left\{a \frac{Y_{t+1}}{K_{t+1}} \lambda_{t+1}+(1-d)\left(\frac{K_{t+1}}{I_{t+1}}\right)^{-d} q_{t+1}\right\}$,

Equation $10 \quad \frac{\theta C_{t}}{\left(L-L_{t}\right)}=(1-a) \frac{Y_{t}}{L_{t}}$.

Equation 7 defines the marginal utility of consumption and equation 8 defines the marginal value of an additional unit of capital in period $t+1$ (the multiplier on equation 6 , $q_{t}$ ). Equation 10 relates the marginal rate of substitution between leisure and consumption to the marginal rate of transformation between leisure and consumption (i.e., the negative of the marginal product of labor)-i.e., the intratemporal condition for optimality. Equation 9 (in combination with equation 8) equates the marginal rate of substitution between current and future consumption to the return to postponed consumption (which involves both the marginal product of capital in production and the marginal product of investment in capital accumulation)—i.e., the intertemporal condition for optimality.

Generally, the set of nonlinear equations that characterize the optimal allocation (equations 1, 2, 4, 6, 7, 8, 9, and 10) do not possess a closed-form solution; however, in the current case, the assumptions regarding functional forms yield a solution via what Long and Plosser (1983) term "dumb luck". In this case, dumb luck consists of a method of undetermined coefficients: guess a form of the decision rules for consumption, investment, and labor input, and verify that a solution of this form satisfies all the firstorder conditions and constraints. A by-product of this procedure is the decision rules in terms of the underlying parameters governing preferences and technology.

Following Long and Plosser (1983), Hercowitz and Sampson (1991), and Benassy (1995), guess that consumption and investment are a constant fraction of output $\left(X=c_{i} Y\right.$ 
for some $\mathrm{c}_{\mathrm{i}}, \mathrm{X}$ equal to $\mathrm{C}$ or $\mathrm{I}$ ) and that labor input is constant. Inserting this guess into the first order conditions, and some algebra yields the solutions

Equation $11 \quad C_{t}=\frac{1-\beta(1-d+d a)}{1-\beta(1-d)} Y_{t}$

Equation $12 \quad I_{t}=\frac{\beta d a}{1-\beta(1-d)} Y_{t}$,

Equation $13 \quad L_{t}=\frac{(1-a) \frac{1-\beta(1-d)}{\beta d a}}{\theta+(1-a) \frac{1-\beta(1-d)}{\beta d a}} L \equiv \bar{L}$.

These solutions are exactly those of Hercowitz and Sampson (1991), who solve the model under expected-utility maximization (i.e., $\chi$ equal to one). Since the solutions for investment and consumption are independent of risk aversion, the time path of the capital stock and output are identical (given the capital accumulation equation 6 and the production function equation 1). Non-expected utility does not alter the business cycle properties of the model at all, regardless of the degree of risk-aversion; the unit intertemporal elasticity of substitution and form of adjustment costs of investment determine the business cycle properties of the model. This result will prove quite useful below in calibrating the model to match asset prices.

Before turning to the welfare cost of business cycles and asset pricing, let's first consider the relationship between these results and other work on business cycles and asset prices that abandon the time-separable, expected utility framework. Jermann (1998) shows that preferences that exhibit habit formation can match certain business cycle characteristics and asset pricing anomalies—e.g., the large equity premium-when combined with adjustment costs of investment; these preferences do so by raising riskaversion, but at the cost of a highly variable risk-free rate in the model. Tallarini (2000) shows that non-expected utility (non-state separable preferences as in this paper) can generate a large equity premium and has only modest implications for the business cycle properties of the model he considers. These results are similar to the finding above that the business cycle properties of the model herein are not affected by separating risk aversion from intertemporal substitution. One stark advantage of the approach in this 
paper is the closed-form solutions. These solutions will provide insight into key parameters governing the welfare effects of business cycles and asset prices. More importantly, the closed-form solutions will facilitate the consideration of a monetary policy that attempts to maximize consumers' welfare in the section 4 ; the numerical approaches followed by Jermann (1998) and especially Tallarini (2000) are relatively new and may be opaque to some economists. ${ }^{5}$ However, the analytical simplicity comes at a cost: In the model of this paper, (the natural logarithms of) consumption and investment have the same variance - a clearly counterfactual implication. As the primary focus below will be the benefit from monetary policy stabilization, not a complete characterization of business cycle fluctuations, the simple model is probably a reasonable first step. Following Rotemberg and Woodford (1997), most recent analyses of monetary policy in simple models do not consider investment dynamics at all.

Returning to the model, it is straightforward to insert equation 12 into equation 6 , and use the resulting equation (with equation 2) to derive the vector-autoregressive process governing output, capital, and technology

Equation $14 \quad \ln Y_{t}=(1-a) \ln \bar{L}+a \ln K_{t}+\left(\ln Z_{t}-\ln Z_{t}^{*}\right)+\ln Z_{t}^{*}$,

\section{Equation 15}

$\ln K_{t+1}=d\left[(1-a) \ln \bar{L}+\ln \frac{\beta d a}{1-\beta(1-d)}\right]+(1-d+d a) \ln K_{t}+d\left[\left(\ln Z_{t}-\ln Z_{t}^{*}\right)+\ln Z_{t}^{*}\right]$

Equation $16 \quad \ln Z_{t}-\ln Z_{t}^{*}=\rho\left(\ln Z_{t-1}-\ln Z_{t-1}^{*}\right)+e_{t}$,

Equation $17 \quad \ln Z_{t}^{*}=\ln Z_{t-1}^{*}+g$.

Equations 14 through 17 show that, conditional on the current capital stock and the current levels of actual and trend productivity $\left(\mathrm{Z}\right.$ and $\left.\mathrm{Z}^{*}\right)$, all quantities variables are lognormally distributed and homoskedastic. Note that the effects of "trend" and actual productivity have been separated, as these components will play separate roles below.

\footnotetext{
${ }^{5}$ Tallarini (2000) solves his model using the discounted linear exponential quadratic gaussian control methods developed in Hansen and Sargent (1995). These methods do not impose certainty equivalence as linear-quadratic approximations do. Whittle $(1981,1990)$ first develops related methods.
} 
The lognormal distributions of quantity variables will prove useful in deriving both welfare and asset pricing implications of the model.

\section{The Implications for Welfare and Asset Pricing}

The analytic solutions for quantity dynamics implied by the model allow a characterization of welfare and asset prices. These results provide insight into the reasons that previous research has often found a low cost of business cycles (e.g., Lucas (1987)), and suggest that-if the degree of risk aversion suggested by asset pricing anomalies such as the equity premium is incorporated into the model — the cost of business cycles may be quite large. The presence of a large cost of business cycles then begs the question of whether stabilization policies that are optimally chosen can deliver a large welfare gain, which is addressed in section 4.

A. The Welfare Cost of Business Cycles

The model implies that consumption is lognormally distributed, with the period $t$ mean of log consumption linked to the current values of capital and productivity through equations 11 and 14. Current utility-equation 3-depends on log consumption, leisure, and a nonlinear function of future expected utility; this nonlinearity makes preferences non-state separable, and divorces the coefficient of relative risk aversion from the intertemporal elasticity of substitution. One might imagine that these complications make it difficult to analytically solve for utility, and hence analytically compute the welfare cost of business cycles. In fact, the closed-form solution of utility is straightforward to derive. As before, employ a variant of the method of undetermined coefficients. Specifically, assume that utility is normally distributed, and that the mean of utility depends upon the same factors that determine the mean of log consumption (a constant, capital, trend productivity, and the deviation from trend productivity). These assumptions, combined with equations 3,11 , and 14 and a little algebra yield ${ }^{6}$

\footnotetext{
${ }^{6}$ The following property of normally distributed random variables is also needed: If $\mathrm{x}$ is normally distributed with mean $m$ and variance $s$, then $E\left\{e^{x}\right\}=e^{m+0.5 s}$.
} 
Equation 18

$$
\begin{aligned}
U_{t}= & u_{1}+u_{2} \ln K_{t}+u_{3} \ln Z_{t}^{*}+u_{4}\left(\ln Z_{t}-\ln Z_{t}^{*}\right), \\
u_{1}= & \frac{1}{1-\beta}\left\{\theta \ln (L-\bar{L})+\ln \frac{1-\beta(1-d+d a)}{1-\beta(1-d)}+(1-a) \ln \bar{L}+\ldots\right. \\
& \beta\left[u_{2} d\left((1-a) \ln \bar{L}+\ln \frac{1-\beta(1-d+d a)}{1-\beta(1-d)}\right)\right]+\ldots \\
& \left.\beta\left[u_{3} g+\frac{1}{2} u_{4}^{2} \frac{(1-\beta)(1-\chi)}{1+\theta} \sigma^{2}\right]\right\} \\
u_{2}= & \frac{a}{1-\beta(1-d+d a)}, \\
& \frac{1-\beta(1-d)}{1-\beta(1-d+d a)} \\
u_{3}= & \frac{1-\beta(1-d)}{1-\beta} \\
u_{4}= & \frac{1-\beta(1-d+d a)}{1-\beta \rho} .
\end{aligned}
$$

While this equation appears a bit unwieldy, especially the constant term, it is straightforward to use equation 18 for the typical welfare cost of business cycle calculations that have often been performed following Lucas (1987), which suggested that the welfare cost of business cycles could be surprisingly small.

These types of calculations typically ask two questions: 1 . How much would a consumer be willing to pay, in units of consumption, in order to eliminate all variability in the consumption stream? or 2. What decrease in the growth rate would the consumer be willing to accept in return for eliminating all variability in consumption? In the framework of this paper, these questions are easy to answer, especially when rephrased as: 1 . How large a decrease in the level of productivity (actual and trend) would a consumer be willing to accept in order to eliminate all variability in the consumption stream? or 2. What decrease in the growth rate of productivity would the consumer be willing to accept in return for eliminating all variability in consumption? The equivalence of the second questions in each case is immediate, as the model possess as 
balanced growth path along which consumption grows at a rate $1 /(1-a)$ times the rate of productivity growth. The similarity of the first question is also apparent from equation 14: if both the trend and actual productivity levels are lowered by one percent, current output is also lowered by one percent, and hence current consumption is lowered one percent. A permanent reduction in the level of productivity also has implications for capital accumulation in the long run that make such a reduction slightly different than a permanent decrease in consumption.

In order to compute the consumer's willingness to make level or growth tradeoffs for increased stability, one first needs the change in utility implied by a given change in the variance of productivity $\left(\Delta \mathrm{U} \mid \Delta \sigma^{2}\right)$, which from equation 18 is

Equation $19 \Delta U \mid \Delta \sigma^{2}=\frac{1}{2} \beta \frac{(1-\chi)}{1+\theta}\left\{\frac{\frac{1-\beta(1-d)}{1-\beta(1-d+d a)}}{1-\beta \rho}\right\}^{2} \Delta \sigma^{2}$.

Equation 19 highlights one important point to remember in the discussion below: in this model, the consumer is unwilling to pay anything for increased stability in the log of productivity (i.e., the change in utility from increased stability is zero) if the coefficient of relative risk aversion is one (i.e., $\chi$ equal to one, which also corresponds to expected utility). This result may at first seem puzzling: surely a risk averse consumer would be willing to pay something to have a smoother stream of consumption. In fact, this result simply reflects the effect of Jensen's inequality and the specification of productivity fluctuations as lognormal. While consumption is smoother if the variance of the productivity shock falls, the expected level of consumption is also lower (because less variability in the log of productivity lowers the mean level of productivity, using the property of a lognormal distribution in footnote 3 ). In the case of expected utility with a coefficient of relative risk aversion/intertemporal elasticity of substitution equal to one, these two effects offset each other in utility terms. The usual practice of offsetting the Jensen's inequality term in the mean of consumption is not followed here because monetary policy or other stabilization policies do not operate in that fashion, as discussed in section 4. 
The central result concerns the magnitude of the utility cost of fluctuations: while risk aversion has no effect on the quantity dynamics of the model, equation 19 makes very clear that a high degree of risk aversion (a high value of $\chi$ ) implies a very large effect of fluctuations on welfare. ${ }^{7}$ To compute this cost in terms of percentage declines in the level of (actual and trend) productivity that a consumer would be willing to pay $\left(\Delta \mathrm{U} \mid\left(\Delta \ln \mathrm{Z}=\Delta \ln \mathrm{Z}^{*}\right)\right)$, consider the change in utility from equation 18

Equation $20 \Delta U \mid\left(\Delta \ln Z=\Delta \ln Z^{*}\right)=\frac{\frac{1-\beta(1-d)}{1-\beta(1-d+d a)}}{1-\beta} \Delta \ln Z^{*}$.

Notice that the change in utility implied by a percentage change in the level of productivity is independent of risk aversion. In an expected utility model, the utility cost of a percentage decline in the level of productivity would depend on the coefficient of relative risk aversion/intertemporal elasticity of substitution. Such dependence reflects the effects of intertemporal substitution, not risk aversion, which is intuitive because the change does not involve risk. The separation of risk aversion and intertemporal substitution - and the analytical characterization of fluctuations and welfare-makes this result very clear.

A computation of the tradeoffs the consumer would be willing to make to remove the variability of productivity is simple given equations 19 and 20: for a given decline in the variance of productivity innovations, find the decline in productivity that equates equations 19 and 20. Table 1 presents such comparisons for two representative calibrations of the stochastic process for productivity - a unit root process and a trend stationary process - that are chosen to match roughly the stochastic process of consumption. Other parameter values are chosen sensibly, as discussed in the footnote to the table.

\section{Insert table 1 here}

\footnotetext{
${ }^{7}$ Remember, the coefficient of relative risk aversion over atemporal wealth gambles is $\frac{\chi+\theta}{1+\theta}$.
} 
Panel A reports the results for the random walk productivity process. Column 1 reports the coefficient of relative risk aversion, column 2 reports the loss in welfare from volatility (which is derived by setting the variance of productivity innovations to zero), and column 3 presents the gain in utility from a one percent increase in productivity. Column 4 presents the loss in the level of productivity that a consumer would accept to eliminate volatility, in percentage points (log-difference). For levels of risk aversion above 25, these figures are large (for example, approaching twenty percentage points for a coefficient of relative risk aversion near 60), reflecting consumers distaste for fluctuations. The welfare costs of business cycles in the model can be several orders of magnitude larger than suggested by Lucas (1987), who places the cost of consumption fluctuations at less than a tenth of a percent of consumption. The figures for a trendstationary process (panel B) are also large, for very high degrees of risk aversion. Tallarini (2000) first notes similar results.

These results raise the question of whether the high degrees of risk aversion associated with a large cost to business cycles are reasonable. The answer to this question cannot be found by considering quantity dynamics, as such dynamics are independent of risk aversion. This result is important, as economists view high degrees of risk aversion as implausible at least in part because in some models high risk aversion leads to very smooth consumption dynamics; for example, Lucas (1987) rejects high degrees of risk aversion as implausible, in part because such high degrees of risk aversion would lead to consumption smoothing under the expected-utility preferences he uses. ${ }^{8}$ To illustrate the "plausibility" of high degrees of risk aversion in the model developed herein, the next sub-section asks what degree of risk aversion is necessary to match the equity premium in the model; this exercise confirms that the welfare cost of business cycles in a "reasonably" parameterized version of the model is high.

\section{B. Asset Pricing}

Non-state separable preferences (Epstein-Zin-Weil preferences) were first applied to asset pricing issues, as a perusal of the references makes clear. The analytical

\footnotetext{
${ }^{8}$ For example, the model with isoelastic utility as in Rouwenhorst (1995) or a model with habit formation such as Jermann (1998); in such models, increasing risk aversion—the importance of habit—while holding other parameters constant, such as adjustment costs of investment, would alter quantity dynamics substantially.
} 
characterization of quantity and utility dynamics suggests that it may be fruitful to consider the asset pricing implications of the model in order to inspect the mechanisms at work, as well as to gauge plausible degrees of risk aversion for the welfare calculations above. The normal distributions of utility and the logs of all quantities make such derivations straightforward.

Following standard practice (e.g., Campbell, Lo, and MacKinlay (1997), Cochrane (2000)), assets can be priced with knowledge of a pricing kernel or stochastic discount factor $\mathrm{M}$. Specifically, the return to an asset $\mathrm{j}$ is determined by the following equation

Equation $21 \quad 1=E_{t}\left\{R_{t+1}^{j} M_{t+1}\right\}$,

where $R_{t+1}{ }^{j}$ is the return on asset $j$ between period $t$ and period $t+1$. The stochastic discount factor $\mathrm{M}$ is given by the ratio of the marginal utility of consumption in period $\mathrm{t}+1$ to the marginal utility of consumption in period $\mathrm{t}$

Equation 22 $M_{t+1}=\frac{\frac{\partial U_{t}}{\partial C_{t+1}}}{\frac{\partial U_{t}}{\partial C_{t}}}=\beta \frac{C_{t}}{C_{t+1}} \frac{e^{\frac{(1-\beta)(1-\chi)}{(1+\theta)} U_{t+1}}}{E_{t}\left\{e^{\frac{(1-\beta)(1-\chi)}{(1+\theta)} U_{t+1}}\right\}}$.

In the expected utility case ( $\chi$ equal to 1 ), equation 22 simplifies to the familiar log-utility case, where the stochastic discount factor is the discounted inverse of consumption growth.

First consider the implications of the model for the risk-free rate: rearranging equation 21 shows that the risk-free rate equals the inverse of the expected value of the stochastic discount factor:

Equation $23 \quad R_{t+1}^{f}=\frac{1}{E_{t}\left\{M_{t+1}\right\}}$.

Substituting the expression for the stochastic discount factor (equation 22) and the laws of motion for consumption and utility (and using standard results regarding expectations of variables with normal distributions) yields the risk-free rate: 
Equation $24 \quad R_{t+1}^{f}=\frac{1}{\beta} e^{a\left(\ln K_{t+1}-\ln K_{t}\right)+(\rho-1)\left(\ln Z_{t}-\ln Z_{t}^{*}\right)+g-\frac{1}{2}\left(1-2 \frac{(1-\beta)(1-\chi)}{1+\theta} u_{4}\right) \sigma^{2}}$.

Higher degrees of risk aversion (i.e., higher values of $\chi$ ) lead to lower values of the riskfree rate, as risk-averse consumers value the safety of sure claims to future consumption.

The return to equity—defined as the return to a claim to capital—can also be easily derived. Consider a decentralized version of the model in section 2 in which firms undertake investment, and issue shares to finance this investment. For simplicity, there is one share that is traded as a claim to the economy's capital stock, with value $V_{t}$ at the end of period $t$ (following the payment of dividends, so $V_{t}$ is the ex-dividend price of the share). The return to an investment in this share is $\left(\mathrm{V}_{\mathrm{t}+1}+\mathrm{D}_{\mathrm{t}+1}\right) / \mathrm{V}_{\mathrm{t}}$, where $\mathrm{D}$ represents the dividend payment (which in turn equals the firm's revenue minus wage payments and investment, Y-WL-I). Using standard arguments, the value of the share will equal the value of the capital stock in terms of consumption; the only complication is that, while the price of investment in terms of consumption is one, the capital adjustment costs implied by equation 6 imply that the price of capital in terms of consumption will differ from one. Denoting the price of capital in terms of consumption by q ${ }^{*}$, and using the unit relative price of investment, yields the following equation for $\mathrm{q}^{*}$

Equation $25 \quad q_{t}^{*}=\left\{\frac{\partial K_{t+1}}{\partial I_{t}}\right\}^{-1}=\frac{1}{d}\left(\frac{I_{t}}{K_{t}}\right)^{1-d}$.

Combining equation 25 with the definition of dividends, the equilibrium law of motion for investment (equation 12), and the wage bill (WN) implied by the Cobb-Douglas production function $((1-\mathrm{a}) \mathrm{Y})$ yields the return to equity

Equation $26 \quad R_{t+1}^{e}=\frac{V_{t+1}+D_{t+1}}{V_{t}}=\frac{q_{t+1}{ }^{*} K_{t+2}+D_{t+1}}{q_{t}{ }^{*} K_{t+1}}=\frac{1}{\beta} \frac{Y_{t+1}}{Y_{t}}$, implying the return to equity is proportional to output growth. Taking expectations of equation 26 yields the expected return to equity 
Equation $27 \quad E_{t}\left\{R_{t+1}^{e}\right\}=\frac{1}{\beta} e^{a\left(\ln K_{t+1}-\ln K_{t}\right)+(\rho-1)\left(\ln Z_{t}-\ln Z_{t}^{*}\right)+g+\frac{1}{2} \sigma^{2}}$.

The equity premium - the log-difference between the return to equity and the risk-free rate-follows directly from equations 24 and 27

Equation 28

$$
\text { Equity premium }=\log \left(E_{t}\left\{R_{t+1}^{e}\right\} / R_{t+1}^{f}\right)=\sigma^{2}\left(1-\frac{(1-\beta)(1-\chi)}{1+\theta} u_{4}\right)
$$

$$
=\sigma^{2}\left(1-\frac{(1-\beta)(1-\chi)}{1+\theta} \frac{\frac{1-\beta(1-d)}{1-\beta(1-d+d a)}}{1-\beta \rho}\right) .
$$

The equity premium is an increasing function of risk aversion; interestingly, as a comparison of equations 27 and 24 illustrates, the larger risk premium associated with higher levels of risk aversion stems from a lower value of the risk-free rate, not higher values of the return to equity. This follows from the production structure of the model: In a model with production, the return to equity is pinned down by the propensity to save and the production technology (as these two factors pin down the marginal product of capital).

To illustrate the types of equity premia that can be delivered by the model, table 2 presents the equity premium implied by the productivity processes (both trend stationary and random walk) from table 1 . The values of the risk-free rate and return to equity are presented for balanced growth levels of productivity and capital $\left(Z_{t}=Z_{t}^{*}, K_{t+1} / K_{t}=g /(1-a)\right)$. The last row of the table reports the risk-free rate and the return to equity in the data; the equity premium is about 4-1/4 percent historically. In the random walk case (panel A), an equity premium close to that observed in the data can be reached with a high degree of risk aversion - a coefficient of relative risk aversion around 200. This is a high degree of risk aversion, and lies well outside the "reasonable" range posited by Mehra and Prescott (1985). It is notable that in the business cycle model herein such a high degree of risk aversion has no effect on quantity fluctuations, because the coefficient of relative risk aversion is not linked to the intertemporal elasticity of substitution; to the extent that high degree of risk aversion are considered implausible because such a high degree of risk aversion would lead to a strong consumption smoothing motive (as in Rouwenhorst (1995) or Jermann (1998)), the model of this paper clearly shows that this is not the case 
with state-separable preferences (as do the numerical exercises in Tallarini (2000) and the extension to include aversion to Knightian uncertainty in Kiley (2001)). In any event, most explanations of the equity premium require high degrees of risk aversion (Campbell, Lo, and MacKinlay (1997), Cochrane (2000)). Moreover, by separating intertemporal substitution and risk aversion, the model herein does not encounter any problems matching both the equity premium and the risk-free rate for plausible discount factors (a problem common to other models (Weil (1989), Campbell, Lo, and MacKinlay (1997)).

\section{Insert table 2 here}

The degrees of risk aversion consistent with a large equity premium are about four times as large if the productivity process is assumed to be stationary, as in this case consumers face substantially less consumption risk (panel B). One common thread across both the random walk and trend stationary cases regards the welfare costs of business cycles implied by the model: If risk aversion is chosen to deliver an equity premium anywhere near the data, the welfare costs of business cycles in table 1 are very large - several orders of magnitude above the suggestion of Lucas (1987).

\section{The Benefit from an Activist Monetary Policy}

While the welfare results above show that business cycles may be very costly, they provide no insight into the benefit from stabilization policies. This result is immediate in the model already presented, as the allocation that characterizes the competitive equilibrium with no distortions is pareto optimal. The calculations above illustrate that consumers may dislike the fluctuations associated with stochastic productivity a great deal, but no policymaker can improve consumer welfare, as the fluctuations in output and consumption stem from nature's stochastic productivity process.

In order to consider a role for stabilization policy, let's suppose that firms' output prices are sticky. If nominal prices are fixed in advance of productivity shocks and firms commit to meeting demand at those fixed prices, the real wage will no longer equal the marginal product of labor of labor and fluctuations will no longer be optimal. Recent research has emphasized these distortions in calculating the welfare losses associated 
with fluctuations in models where consumers maximize expected utility (following the influential contribution of Rotemberg and Woodford (1997)).

To introduce a role for money, assume that output is proportional to real money balances

Equation $29 \quad \frac{M_{t}}{P_{t}}=\kappa Y_{t}$,

where $\mathrm{M}$ is the nominal money supply and $\mathrm{P}$ is the nominal price level. While the introduction of a quantity equation like equation 29 may appear ad hoc, it is straightforward to introduce a similar equation by assuming that real balances enter the utility function (as in the appendix). Importantly, the role of real balances in the utility function is ignored in the welfare calculations below. Rotemberg and Woodford (1997) suggest that such a decision is appropriate when analyzing stabilization policy; the Friedman-rule prescriptions that fall out of typical "microfoundations" that introduce money are not followed in practice by central banks, suggesting that the role of real balances in welfare-outside of the stabilization possibilities introduced by fiat moneymay be small. In any event, recent research has ignored these effects, and this study will follow the same procedure. ${ }^{9}$

Sticky nominal prices are introduced in the simplest way that preserves the analytical solutions for output and price fluctuations. Specifically, assume that firms set $(\log )$ prices prior to the productivity realization so that the level of output and employment are expected to reach their flexible price levels:

Equation $30 \quad \ln P_{t}=E_{t-1}\left\{\ln M_{t}-\ln Y_{t}^{f l e x}\right\}-\ln \kappa$, where $Y_{t}^{\text {flex }}$ is the flexible price level of output given in equation $14 .^{10}$

Combining the price level equation and the aggregate demand relationship given by equation 29 with the production function yields the processes for output and labor input:

\footnotetext{
${ }^{9}$ The appendix provides more details.

${ }^{10}$ At this point, the reader may object that sticky nominal prices are normally motivated with imperfect competition. It is trivial to extend the model to include monopolistic competition in the traditional manner (e.g., Rotemberg and Woodford (1997)); so long as fiscal policy is set to remove the distortionary effects of monopolistic competition (as is traditionally done in welfare analyses), none of the discussion herein is altered.
} 
Equation $31 \quad \ln Y_{t}=M_{t}-E_{t-1}\left\{M_{t}\right\}+(1-a) \ln \bar{L}+a \ln K_{t}+\rho\left(\ln Z_{t-1}-\ln Z_{t-1}^{*}\right)+\ln Z_{t}^{*}$,

Equation 32

$$
\ln L_{t}-\ln \bar{L}=\frac{1}{1-a}\left[\left(M_{t}-E_{t-1}\left\{M_{t}\right\}\right)-\left(\ln Z_{t}-\ln Z_{t}^{*}-\rho\left(\ln Z_{t-1}-\ln Z_{t-1}^{*}\right)\right)\right],
$$

Two important aspects of equations 31 and 32 are immediate: 1. Labor supply will fluctuate in response to unexpected movements in productivity and money, and such fluctuations are inefficient (as labor supply is constant under the optimal allocation); 2. The monetary authority can implement the optimal allocation by setting the innovation in the money supply equal to the innovation in productivity, which offsets the aggregate demand constraint (equation 29). Also, it is straightforward to show that, conditional on the path of output, the processes for consumption and investment (equations 11 and 12) are the same in the sticky-price model.

Since monetary policy can implement the optimal allocation, one might imagine that the benefit to the representative consumer from such action is substantial. To consider that possibility, one must first define what an alternative monetary policy would be. Suppose the alternative is a deterministic monetary policy in which the money supply grows at some constant rate-and hence does not respond to any exogenous shock. ${ }^{11}$ In this case, labor input will fall in response to a positive productivity innovation, and output will remain constant (equations 31 and 32) until the period following the shock. To derive the level of welfare under this policy, one can proceed as in section 3: Assume that utility has a normal distribution whose conditional mean depends upon the capital stock and the productivity process, and use the log-normal processes for the variables that enter the utility function and the method of undetermined coefficients to solve for the utility process. Unfortunately, this procedure will not yield an exact solution in the case with labor fluctuations because utility depends upon leisure, which equals the difference between the labor endowment and labor supply and is not lognormally distributed (even though labor supply is log-normally distributed).

\footnotetext{
${ }^{11}$ Note that the choice of the growth rate of the money supply that is optimal will be determined by the microeconomics behind equation 29 , which are ignored.
} 
Therefore, consider an approximate solution, where the disutility from labor supply is approximated by

Equation $33 \quad \theta \ln \left(L-L_{t}\right)=\theta \ln (L-\bar{L})-\frac{\theta \bar{L}}{L-\bar{L}}\left(\ln L_{t}-\ln \bar{L}\right)-\frac{1}{2} \theta\left(\frac{\bar{L}}{L-\bar{L}}\right)^{2}\left(\frac{1}{1-a}\right)^{2} \sigma^{2}$.

Equation 33 is a first-order Taylor-series approximation of the disutility of labor supply around the expected level of labor supply. The log deviation is used, rather than the level deviation, as then utility will be (approximately) normally distributed. Also, the last term in the approximation is the expectation of the second-order terms in a Taylor-series approximation; including these expectations improves the average accuracy of the approximation, while preserving the normal distribution of utility. ${ }^{12}$

Given equation 33, proceed as in section 3: assume that utility is normally distributed, and that the mean of utility depends upon the same factors that determine the mean of log consumption (a constant, capital, trend productivity, and the deviation from trend productivity), yielding (with equations 3, 11, 31, 32, 33 and a deterministic path for the money supply)

\footnotetext{
${ }^{12}$ Directly including the second-order terms would eliminate the normal distribution; the square of a normally distributed variable has a chi-square distribution. Kim and Kim (2000) discuss the importance of including the mean of second-order terms in welfare calculations.
} 


\section{Equation 34}

$$
\begin{aligned}
U_{t}= & u_{1}+u_{2} \ln K_{t}+u_{3} \ln Z_{t}^{*}+u_{4} \rho\left(\ln Z_{t-1}-\ln Z_{t-1}^{*}\right)+u_{5} e_{t}, \\
u_{1}= & \frac{1}{1-\beta}\left\{\theta \ln (L-\bar{L})+\ln \frac{1-\beta(1-d+d a)}{1-\beta(1-d)}+(1-a) \ln \bar{L}+\ldots\right. \\
& \beta\left[u_{2} d\left((1-a) \ln \bar{L}+\ln \frac{1-\beta(1-d+d a)}{1-\beta(1-d)}\right)\right]+\ldots \\
& \beta\left[u_{3} g+\frac{1}{2} u_{5}^{2} \frac{(1-\beta)(1-\chi)}{1+\theta} \sigma^{2}\right]-\ldots \\
& \left.\frac{1}{2} \theta\left(\frac{\bar{L}}{L-\bar{L}}\right)^{2}\left(\frac{1}{1-a}\right)^{2} \sigma^{2}\right\}, \\
u_{2}= & \frac{a}{1-\beta(1-d+d a)}, \\
u_{3}= & \frac{1-\beta(1-d+d a)}{1-\beta}, \\
u_{4}= & \frac{1-\beta(1-d+d a)}{1-\beta(1-d)} \\
u_{5}= & \frac{\theta \bar{L}}{L-\bar{L}} \frac{1}{1-a}+\beta \rho u_{4} .
\end{aligned}
$$

This expression is very similar to equation 18: The differences appear to lie in the effect of the innovation $\left(\mathrm{u}_{5}\right)$ and the additional term in the intercept involving the variance, and both of these differences clearly arise because of variable labor supply.

However, these equations can be simplified: A sticky price level does not alter the equality between the marginal rate of substitution between labor supply and the real wage:

$$
\frac{\theta}{L-L_{t}}=\frac{W_{t}}{P_{t}} \frac{1}{C_{t}}
$$


On average (i.e., at $\mathrm{L}_{t}$ equal to the optimal labor supply), the real wage equals the marginal product of labor; combining this with equation 11 for consumption yields

$$
\begin{aligned}
& \frac{\theta \bar{L}}{L-\bar{L}}=(1-a) \frac{1-\beta(1-d)}{1-\beta(1-d+d a)}, \text { or } \\
& \qquad \frac{\theta \bar{L}}{L-\bar{L}} \frac{1}{(1-a)}=\frac{1-\beta(1-d)}{1-\beta(1-d+d a)} .
\end{aligned}
$$

Inserting this equality into the equation for $\mathrm{u}_{5}$ shows that $\mathrm{u}_{5}$ equals $\mathrm{u}_{4}$, and hence the only difference between utility under the deterministic monetary policy—with no stabilization-and the optimal monetary policy (the difference between equation 34 and equation 18) is

Equation $35 \Delta U \mid$ Optimal M.P. $=-\frac{1}{2} \theta\left(\frac{\bar{L}}{L-\bar{L}}\right)^{2}\left(\frac{1}{1-a}\right)^{2} \sigma^{2}=-\frac{1}{2} \frac{1}{\theta}(1-\beta \rho)^{2} u_{4}^{2} \sigma^{2}$.

Finally, dividing this loss from an absence of stabilization policy by the loss from a percentage point reduction in productivity in equation 20 to provide a measure of the potential gains from stabilization policy yields

Equation $36 \quad$ Stabilization Benefit $=\frac{1}{2} \frac{1}{\theta}(1-\beta) \frac{1-\beta(1-d)}{1-\beta(1-d+d a)} \frac{\sigma^{2}}{\Delta \ln Z^{*}}$.

This stabilization benefit is likely to be very small, as the discount factor lies near one. The trivial gain implied by the factor (1- $\beta$ ) in equation 36 arises because stabilization policy only removes the distortion that arises over the period of price stickiness; if this period in only a year or so, medium-run fluctuations faced by the consumer are not much affected by monetary policy.

Moreover, this benefit of stabilization policy does not depend on risk aversion, so the high values of risk aversion necessary to match asset market data do not yield a large benefit to stabilization policy. This result is actually intuitive: stabilization policy, in an environment where sticky-prices are the primary distortion, only serves to recreate the optimal allocation, which still includes the risk delivered by a stochastic productivity 
environment. Without stabilization policy, this risk affects both labor supply and consumption fluctuations, which causes inefficient movements through time in labor input and consumption. However, the overall amount of risk faced by consumers is not much affected by stabilization policy.

To gauge the quantitative magnitude of the gain from stabilization policy, consider the gains that are implied by the random walk and stationary productivity processes used in table 1. According to these processes (and finding the change in productivity that sets equation 36 to one), consumers under the random walk process would give up less than 0.00009 percent of the level of productivity for the optimal monetary policy, and consumers facing the stationary productivity process would give up about 0.00008 percent of the level of productivity for the optimal monetary policy. These gains are many orders of magnitude smaller than those in table 1; monetary policy can eliminate only a fraction of business cycle risk in the model of this paper. In fact, these gains from stabilization policy are orders of magnitude smaller than the welfare costs of business cycles in Lucas (1987), which most economists consider trivial, because the results of Lucas refer to the elimination of all consumption risk at an unchanged mean level of consumption, and monetary policy cannot remove all consumption risk.

Should the trivial benefits associated with stabilization policy in this paper be taken seriously? From one perspective, the answer is yes: A large body of recent work has pursued models in which rigid prices are the primary distortion and fluctuations are driven by the standard shocks of dynamic general equilibrium models, i.e., productivity shocks and government spending shocks. ${ }^{13}$ A growing literature examines the welfare losses in such models (following Rotemberg and Woodford (1997)); unlike in this paper, this work does not consider the absolute level of the gains to stabilization policy, but rather considers the relative gains of certain policies. While the types of price rigidities modeled in this recent work are often more complicated than the price rigidity mentioned above, broadly speaking the models are similar, and hence the welfare calculations in this paper show that optimal policies in such work are likely to have trivial benefits-even if

\footnotetext{
${ }^{13}$ For references to early contributions to the neo-Monetarist synthesis literature, see Rotemberg and Woodford (1997).
} 
one accepts the very large distaste for fluctuations that consumers may have if risk aversion is sufficiently high, as in section 3. In old-fashioned terms, monetary policy in the recent literature focuses on eliminating the Harberger triangles that arise from nominal price stickiness - as Harberger triangles are small relative to Okun's gaps (Tobin (1987)).

From another perspective, the benefits from stabilization policy derived above may be much too small: Such small losses arise because in the model fluctuations are driven by productivity disturbances, which yield large fluctuations even in the optimal allocation. While most recent work is similar, traditional Keynesian analysis often argued that fluctuations were a pathological response to shifts in animal spirits or other factors that would not yield fluctuations under an optimal allocation. Under this view, the welfare gains from stabilization policy could be quite large- on the order of magnitude of the costs of fluctuations in section 3-because much of monetary policy would be responding to Okun's gaps. However, little progress has been made in developing quantitative business cycle models based on microfoundations in which fluctuations are primarily an inefficient response to animal spirits or the result of shifts between multiple but pareto-ranked equilibria (beyond the illustrative work following Farmer (1993), which largely ignores stabilization policy).

\section{Summary}

The model of this paper describes an economy subject to productivity fluctuations that possesses an analytical solution for quantity and asset price movements when consumers' preferences are not state-separable (the non-expected utility preferences of Epstein-ZinWeil). While the assumptions on functional form required to deliver analytical solutions are special, several results emerge clearly. First, it is the intertemporal elasticity of substitution that is critical for quantity fluctuations following shocks, not risk aversion. In addition, the welfare costs of fluctuations are very large when the model is calibrated to match the equity premium, because a large equity premium reflects a distaste for risk and the consumption risk faced by consumers is substantial. Both of these results can also be found in Tallarini (2000), but the numerical techniques used in that piece are 
relatively new and unfamiliar to many economists-so the analytical results herein should help facilitate future work.

More importantly, the characterization of fluctuations also allowed consideration of a sticky-price version of the model, which provides a role for an active monetary policy. Monetary policy can improve welfare by offsetting the effects of sticky prices on labor and output fluctuations. While monetary policy can be very effective in this regard (and in fact can implement the optimal policy in the model), the benefit to such a stabilization policy is trivial. The small gains to stabilization policy arise from the limited potential role of stabilization policy: Most fluctuations reflect the (efficient) movements induced by fluctuations in productivity. In fact, the benefit of stabilization policy is independent of risk aversion in the model, so even calibrated versions of the model in which consumers dislike fluctuations to an arbitrarily large degree yield trivial benefits to stabilization policy.

The emphasis on the role of stabilization policy—rather than simply the welfare costs of fluctuations - is a step beyond the work of Lucas (1987) and others in illustrating that a large cost of fluctuations need not imply a large benefit to stabilization policy. A large and growing literature uses sticky-price models that are broadly similar to the model in this paper to address questions regarding optimal monetary policy design. Since the gains to optimal policies are so small, this literature's focus is basically unimportant given the framework used. This result is unsurprising upon reflection: Optimal monetary policy in New-Keynesian models like that of this paper is solving a taxation problem (i.e., removing the distortion arising from sticky prices), and hence the gain from optimal monetary policy can only be as large as the appropriate Harberger triangle. And the profession has known for a long time that it takes a lot of Harberger triangles to fill an Okun's gap. ${ }^{14}$ Perhaps research that questions the assumption that the fluctuations in the economy represent a response to productivity or other exogenous shocks, and pursues the notion that fluctuations are inefficient response to sunspot shocks or shifts between pareto-ranked equilibria (and hence allows Okun's gaps), could find a larger role for stabilization policy. This question is ripe for further research.

\footnotetext{
${ }^{14}$ The classic reference is Tobin (1987).
} 


\section{References}

Abel, Andrew (2000) The Effects of a Baby Boom on Stock Prices and Capital Accumulation in the Presence of Social Security. Mimeo (October).

Basu, Parantap (1987) An Adjustment Cost Model of Asset Pricing. International Economic Review 28:609-621.

Benassy, Jean-Pascal (1995) Money and Wage Contracts in an Optimizing Model of the Business Cycle. Journal of Monetary Economics 35:303-315.

Campbell, John, Andrew Lo and Craig MacKinlay (1997) The Econometrics of Financial Markets. Princeton University Press, Princeton, NJ.

Cochrane, John (2000) Asset Pricing. Unpublished manuscript (June).

Epstein, Larry and Stanley Zin (1989) Substitution, Risk Aversion, and the Temporal Behavior of Consumption and Asset Returns: A Theoretical Framework. Econometrica 57:937-968.

Epstein, Larry and Stanley Zin (1990) First-Order Risk Aversion and the Equity Premium Puzzle. Journal of Monetary Economics 26:387-407.

Epstein, Larry and Stanley Zin (1991) Substitution, Risk Aversion, and the Temporal Behavior of Consumption and Asset Returns: An Empirical Investigation. Journal of Political Economy 99:263-286.

Farmer, Roger E.A. (1993) The Macroeconomics of Self-Fulfilling Prophecies. The MIT Press, Cambridge, MA.

Gilboa, I. and David Schmeidler (1989) Maxmin Expected utility with Nonunique Prior. Journal of Mathematical Economics 18:141-153.

Hansen, Lars and Thomas Sargent (1995) Discounted Linear Exponential Quadratic Gaussian Control. IEEE Automatic Transactions on Automatic Control. 40:968971.

Hercowitz, Zvi and Michael Sampson (1991) Output Growth, the Real Wage, and Employment Fluctuations. American Economic Review 81:1215-37. Jermann, Urban (1998) Asset Pricing in Production Economies. Journal of Monetary Economics 41:257-275.

Kim, Jinill, and Sunghyun Henry Kim (2000) Spurious Welfare Reversals in Business Cycle Models. Mimeo, University of Virginia. 
Long, John and Charles Plosser (1983) Real Business Cycles. Journal of Political Economy 91: 39-69.

Lucas, Robert E., Jr. (1987) Models of Business Cycles. Basil-Blackwell Ltd., Oxford. Mehra, R. and Edward C. Prescott (1985) The Equity Premium: A Puzzle. Journal of Monetary Economics 15:145-161.

Rotemberg, Julio J., and Michael Woodford (1997) An Optimization-Based Framework for the Econometric Evaluation of Monetary Policy Rules. NBER Macroeconomics Annual 297-346.

Rouwenhorst, K. Geert (1995) Asset Pricing Implications of Equilibrium Business Cycle Models. In Cooley, Thomas, ed. Frontiers of Business Cycle Research. Princeton University Press, Princeton, NJ.

Sargent, Thomas (1987) Dynamic Macroeconomic Theory. Harvard University Press. Cambridge, MA.

Storesletten, Kjetil, Christopher Telmer, and Amir Yaron. (2000) The Welfare Cost of Business Cycles Revisited: Finite Lives and Cyclical Variation in Idiosyncratic Risk. NBER Working Paper 8040.

Tallarini, Thomas (1996) Risk Sensitive Real Business Cycles. Unpublished PhD Dissertation, Department of Economics, University of Chicago.

Tallarini, Thomas (2000) Risk Sensitive Real Business Cycles. Journal of Monetary Economics.

Taylor, John B., ed. (1999) Monetary Policy Rules. University of Chicago Press.

Tobin, J. (1987) "Taxes, Savings and Inflation", in Tobin, J., Essays in Economics, Vol. 1, Macroeconomics, MIT Press, pp. 99-108.

Weil, Philippe (1990) Non-expected Utility in Macroeconomics. Quarterly Journal of Economics 105:29-42.

Whittle, Peter (1981) Risk Sensitive Linear/Quadratic/Gaussian Control. Advances in Applied Probability 13:764-777.

Whittle, Peter (1990) Risk Sensitive Optimal Control. John Wiley and Sons, New York. 


\section{Appendix: A brief guide to an optimizing version of the monetary economy}

Suppose, as in, for example, Benassy (1995), that the utility function in equation 3 is replaced by

\section{Equation 37}

$U_{t}=\ln C_{t}+\theta \ln \left(L-L_{t}\right)+\eta \ln \left(\frac{M_{t}}{P_{t}}\right)+\frac{\beta(1+\theta)}{(1-\beta)(1-\chi)} \ln E_{t}\left\{e^{\frac{(1-\beta)(1-\chi)}{(1+\theta)} U_{t+1}}\right\}$,

where $\mathrm{M} / \mathrm{P}$ are real balances. In addition, the budget constraint facing the consumer is modified to include real balances. It is straightforward to show, as in Benassy (1995), that these preferences give rise to a money demand function of the form in equation 29. The effect of real balances on utility is ignored in the calculations in the text, following Rotemberg and Woodford (1997) and other research. 
Table 1: Welfare Losses ${ }^{*}$

(1)

(2)
A. Random Walk Case

(3)

(4)

Productivity

Sacrifice

0.4852

0.4852

0.4852

0.4852

0.4852

0.4852

0.4852

B. Trend Stationary Case

(3)

(4)

Productivity

Sacrifice

0.0000

$-0.5274$

$-1.0767$

$-5.4714$

$\begin{array}{ll}0.4852 & -10.9648 \\ 0.4852 & -16.4582\end{array}$

0.4852

${ }^{1}$ Coefficient of Relative Risk Aversion, $\frac{\chi+\theta}{1+\theta}$.

*Parameter values: The discount factor $(\beta)$ equals 0.9724 , the depreciation parameter $(d)$ equals 0.10 , and the capital income share (a) equals 0.33 . The weight of leisure in utility $(\theta)$ equals 3 . The growth rate of trend productivity $(\mathrm{g})$ is chosen so that income and consumption grow at 3.2989 percent per year. In the random walk case, the innovation to consumption growth has a variance of 0.000144 ; in the trend stationary case, $\rho$ equals 0.920698 , and the innovation has a variance of 0.000133 . These parameterizations match the random walk and trend-stationary processes for nondurables and services consumption (chain weighted, 1996 dollars) over the 1955-1999 period (annual frequency). 
Table 2: Equity Premium*

(1)

\begin{tabular}{|c|c|}
\hline \multicolumn{2}{|c|}{$\log \left(E_{t}\left\{R_{t+1}{ }^{e}\right\}\right)$} \\
\hline 1 & 0.0609 \\
\hline 25 & 0.0562 \\
\hline 50 & 0.0514 \\
\hline 100 & 0.0417 \\
\hline 150 & 0.0320 \\
\hline 200 & 0.0223 \\
\hline 225 & 0.0174 \\
\hline
\end{tabular}

(3)

\begin{tabular}{lr}
\multicolumn{2}{c}{$\log (4)$} \\
0.0610 & 0.0001 \\
0.0610 & 0.0048 \\
0.0610 & 0.0097 \\
0.0610 & 0.0194 \\
0.0610 & 0.0291 \\
0.0610 & 0.0388 \\
0.0610 & 0.0436
\end{tabular}

(1)

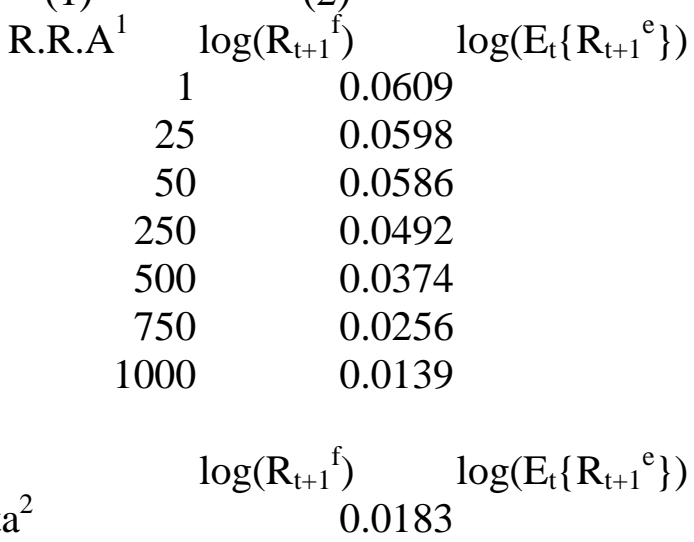

(3)

\begin{tabular}{lr}
\multicolumn{2}{c}{$\operatorname{l}(4)$} \\
\multicolumn{2}{c}{$\log \left(\mathrm{E}_{\mathrm{t}}\left\{\mathrm{R}_{\mathrm{t}+1}^{\mathrm{e}}\right\} / \mathrm{R}_{\mathrm{t}+1}{ }^{\mathrm{f}}\right)$} \\
0.0610 & 0.0001 \\
0.0610 & 0.0013 \\
0.0610 & 0.0024 \\
0.0610 & 0.0119 \\
0.0610 & 0.0236 \\
0.0610 & 0.0354 \\
0.0610 & 0.0472 \\
\multicolumn{2}{c}{$\log \left(\mathrm{E}_{\mathrm{t}}\left\{\mathrm{R}_{\mathrm{t+1}}{ }^{\mathrm{e}}\right\} / \mathrm{R}_{\mathrm{t+1}}{ }^{\mathrm{f}}\right)$} \\
0.0601 & 0.0418
\end{tabular}

(

${ }^{1}$ Coefficient of Relative Risk Aversion, $\frac{\chi+\theta}{1+\theta}$.

B. Trend Stationary Case

lk Case 